\title{
Chronic Kidney Disease and Associated Factors Among HIV Infected Patients Taking Tenofovir Disoproxil Fumarate Based Regimen in Ethiopia: A Hospital-Based Cross-Sectional Study
}

This article was published in the following Dove Press journal:

HIVIAIDS - Research and Palliative Care

\author{
Abebe Muche Belete (iD) \\ Taklo Simeneh Yazie (iD) ${ }^{2}$ \\ 'Department of Medicine, College of \\ Medicine and Health Sciences, Debre \\ Berhan University, Debre Berhan, \\ Amhara, Ethiopia; ${ }^{2}$ Pharmacology Unit \\ and Research Team, Department of \\ Pharmacy, College of Health Sciences, \\ Debre Tabor University, Debre Tabor, \\ Amhara, Ethiopia
}

Background: Life expectancy of HIV patients has increased by the extensive use of antiretroviral therapies (ART), but ART predisposes patients to chronic non-communicable diseases including chronic kidney disease (CKD). Tenofovir disoproxil fumarate is one of the commonly used drugs in ART and is found to have more risk for developing CKD. In the study areas, there was no previous study addressing the prevalence of $\mathrm{CKD}$, so the purpose of this study was to pinpoint the prevalence of CKD, and its associated factors.

Methods: A hospital-based cross-sectional study was employed at Tikur Anbessa Specialized Hospital (TASH) and Zewuditu Memorial Hospital (ZMH) from April 1 to June 30, 2019. The study participants were proportionally allocated to each hospital and a total of 243 eligible participants were selected conveniently from the two hospitals in the study period. Structured questionnaire and checklist were used to collect socio-demographic and clinical data of the participants. Blood samples $(3-5 \mathrm{ml})$ were used to determine serum creatinine using calibrated fully automated Mind ray BS-200E, and glomerular filtration rate (GFR) was estimated using a chronic kidney disease epidemiology equation. Multivariate logistic regression was employed to identify factors associated with CKD, and a P-value of less than 0.05 was considered significant.

Results: In the present study, the prevalence of CKD (GFR $<60 \mathrm{ml} / \mathrm{min} / 1.73 \mathrm{~m}^{2}$ ) was $4.53 \%$ $(95 \% \mathrm{CI}=2.3-8 \%)$. GFR was classified into stages, stage 5 (GFR $<15)$, stage $4(15-29.9)$, stage 3 (30-59.9), stage 2 (60-89.9), and stage 1 ( $\geq 90)$ were $0 \%, 0.4 \%, 4.1 \%, 38.3 \%$, and $57.2 \%$, respectively. In the multivariate logistic regression, age greater than 50 years old, and having cancer were significantly associated with $\mathrm{CKD}$ (AOR: $0.22,95 \% \mathrm{CI}=0.05-0.88, \mathrm{P}=$ 0.033 , and AOR: $18.20,95 \% \mathrm{CI}=122-271.77, \mathrm{P}=0.035$, respectively).

Conclusion: Chronic kidney disease in HIV-infected patients receiving a TDF-based regimen requires attention. Age $>50$ years old, and having cancer as comorbidity were significantly associated with chronic kidney disease. Patients should be regularly monitored for early diagnosis and management of chronic kidney disease in a TDF-based regimen.

Keywords: chronic kidney disease, tenofovir disoproxil fumarate, human immunodeficiency virus, factors, Ethiopia

\section{Background}

Human immunodeficiency virus (HIV) is a major public health problem and globally, more than 36 million adults are living with it. At the end of 2019, 75.7 million people had become infected with HIV and more than 32 million people had died from
Correspondence: Taklo Simeneh Yazie Email taklosimeneh23@gmail.com 
acquired immunodeficiency syndrome (AIDS) related illness since the start of the epidemic. ${ }^{1}$ Sub-Saharan Africa carries the highest burden of HIV and in Ethiopia, 722,248 people were living with HIV in 2017. ${ }^{2}$ Life expectancy in HIV patients has increased by the extensive use of antiretroviral therapies (ART), but ART predisposes patients to chronic non-communicable diseases, including chronic kidney disease (CKD). ${ }^{3}$

The World Health Organization recommends a tenofovir disoproxil fumarate (TDF) based regimen as the preferred regimen for the treatment of HIV/AIDS in adults. ${ }^{4}$ However, ART containing TDF and ritonavir has shown increased risk of developing $\mathrm{CKD}^{5,6}$ and a considerable percent of CKD was found in patients receiving a TDF-based regimen in different countries. ${ }^{6-13}$ TDF is known to affect the renal parenchyma, and it causes mitochondrial toxicity which results in proximal renal tubular dysfunction. How TDF decreases glomerular filtration rate is not precisely known; it may occur secondary to proximal renal tubular dysfunction or independently. ${ }^{14}$ Several factors have been identified to be associated with CKD in the TDF-based regimen such as being female, older age, CD4 count less than 200 cells $/ \mathrm{mm}^{3}$, body mass index (BMI) less than $18.5 \mathrm{~kg} / \mathrm{m}^{2}$, and longer duration of exposure to the TDF-based regimen. ${ }^{7,12,13} \mathrm{In}$ Ethiopia, a TDF-based regimen is the preferred regimen for the treatment of adult HIV-infected patients. However, there are scarce studies on the safety of TDF-based regimens regarding renal function and there is no routine monitoring of renal function in TDF-based regimens. Therefore, the present study aimed to assess CKD and associated factors in TDF-based regimens at Tikur Anbessa Specialized Hospital (TASH) and Zewditu Memorial Hospital (ZMH).

\section{Patients and Methods}

\section{Study Setting and Design}

This study was conducted in TASH and ZMH which are located Addis Ababa, the capital city of Ethiopia. A hospital-based cross-sectional study design was employed among HIV infected patients treated with a TDF-based regimen and the study period was from April 1 to June 30, 2019.

\section{Study Population and Sample}

AllAdult HIV-infected patients aged $\geq 18$ years old and treated with a TDF-based regimen for at least 6 months were included in the study. The study participants were selected proportionally from each hospital and a convenient sampling technique was used to include a total of 243 adult HIV-infected patients on a TDFbased regimen visiting the selected hospitals during the data collection period from April 1 to June 30, 2019. Verbal informed consent was approved by Institutional Ethical Review Board of College of Medicine and Health Sciences, Debre Berhan University. Participants gave verbal informed consent after they were told about the purpose, method, and the ethical concerns of the study. HIV-infected patients who fulfilled the inclusion criteria, gave informed consent, and were adhering to their treatment were included in the study. Adherence was assessed with a visual analog scale (VAS) which has 100 points (0-100), 0 indicating absolute non-adherence and 100 indicating excellent adherence in the last 30 days. ${ }^{15}$ VAS score of at least $95 \%$ was defined as optimal adherence, ${ }^{16}$ and we considered patients with this point as adherent. Pregnant women, patients receiving ART other than a TDF-based regimen, patients with non-adherence, suboptimal adherence, unable to give consent, critical illness or cognitive impairment were excluded.

\section{Data Collection Procedure and Quality Control}

An interviewer-administered structured questionnaire was developed to collect socio-demographic and clinical data of the participants. First, the questionnaire was written in English and then translated to Amharic language. The questionnaire was retranslated into English by an expert to ensure its consistency. A half day of training was given to two senior nurses and laboratory technologists about the objective, methodology and ethical issues of the study. Two nurses collected data using the structured questionnaire and a checklist and two laboratory technologists determined serum creatinine levels. Pretest was done on $5 \%$ of the sample to check the validity of the questionnaire and the checklist. In addition, the completeness of the data was checked daily by the principal investigator.

A checklist was used to collect baseline CD4 count, previous ART and other clinical traits that the patient failed to recall. Seca 761 weight scales with height ruler (with meter reading) attached to it was used to measure weight and height (made in Germany). A simple formula of weight in kilograms divided by height in meters squared was used to calculate body mass index (BMI). 


\section{Laboratory Parameter Determination}

About $3-5 \mathrm{~mL}$ of venous blood with serum (gel) separator tube was collected and a serum sample was immediately separated from the collected venous blood after the blood sample clotted and was centrifuged at 1000-2000 g for 10 minutes. The separated serum was transferred to a Nunc tube and kept frozen at $-20{ }^{\circ} \mathrm{C}$ until processed. Then, serum creatinine was determined using a calibrated fully automated Mind ray BS-200E clinical chemistry analyzer (China) according to the reagent manufacturer's instruction in central laboratory of ZMH and reported in $\mathrm{mg} / \mathrm{dl}$.

CKD was defined as either kidney damage or glomerular filtration rate $(\mathrm{GFR})<60 \mathrm{ml} / \mathrm{min} / 1.73 \mathrm{~m}^{2}$ for 3 months or more, irrespective of cause. ${ }^{17}$ GFR was estimated by using the Chronic kidney disease epidemiology equation which is recommended to calculate GFR for patients with HIV. ${ }^{18}$ GFR in black males and females was estimated by CKD EPI equations as follows:

- For female with serum creatinine $\leq 0.7 \mathrm{mg} / \mathrm{dl}$; GFR $=$ $166 \times(\mathrm{Scr} / 0.7)^{-0.329} \times(0.993)^{\mathrm{Age}}$ and with serum creatinine $>0.7 \mathrm{mg} / \mathrm{dl} ; \mathrm{GFR}=166 \times(\mathrm{Scr} / 0.7)^{-1.209}$ $\times(0.993)^{\text {Age }}$

- For male with serum creatinine $\leq 0.9 \mathrm{mg} / \mathrm{dl}$; GFR $=$ $163 \times(\mathrm{Scr} / 0.9)^{-0.411} \times(0.993)^{\mathrm{Age}}$ and with serum creatinine $>0.9 \mathrm{mg} / \mathrm{dl} ; \mathrm{GFR}=163 \times(\mathrm{Scr} / 0.9)^{-1.209}$ $\times(0.993)^{\text {Age. } 19}$

Where, age in year and serum creatinine in $\mathrm{mg} / \mathrm{dl}$.

\section{Data Analysis}

All data were checked for completeness visually and then entered into SPSS version 21.0 for analysis. Percentage, mean and standard deviation were used to describe patients' characteristics. Bivariate logistic regression was used to assess the crude association between independent variables and $C K D$, and a variable with $p$-value $\leq 0.25$ was considered for multivariate logistic regression. In multivariate logistic regression, a p-value $<0.05$ was considered statistically significant.

\section{Results}

\section{Characteristics of Study Participants}

A total of 243 study participants were included in the final analysis and the majority of them $(149,61.3 \%)$ were female. The median age of the participants was 40 years old, ranging from 18-67 years old. Most of the participants $(125,51.4 \%)$ engaged in private work and $178(73.2 \%)$ had attended above primary education. From a total of study participants, $146(60.1 \%)$ were treated with TDF+lamivudine (3TC)+efavirenz (EFV) and the remaining 97 (39.9\%) participants received TDF $+3 \mathrm{TC}+$ atazanavir boosted with ritonavir (ATV/r). The median duration of HIV infection since diagnosis and treatment with a TDF-based regimen was 112 and 87 months, respectively. The majority of participants (162, 66.7\%) had baseline CD4 count less than 200 cells $/ \mathrm{mm}^{3}$ and the mean \pm standard deviation of GFR of the participants was $96.74 \pm 24.69 \mathrm{ml} / \mathrm{min} / 1.73 \mathrm{~m}^{2}$ (Table 1).

\section{Prevalence of Chronic Kidney Disease Among Study Participants}

By using the CKD-EPI GFR estimator, most of the study participants had GFR of $\geq 90 \mathrm{ml} / \mathrm{min} / 1.73 \mathrm{~m}^{2}$, and the prevalence of CKD was 11 (4.5\%). When kidney function was classified into stages, about 139 (57.2\%) had stage 1 , $93(38.3 \%)$ had stage $2,10(4.1 \%)$ had stage 3, and 1 $(0.4 \%)$ had stage 4 (Table 2). Among participants with CKD, 8 (72.73\%) were female, and 7 (63.64\%) were $\leq 50$ years old. Regarding the type of TDF-based regimen, $8(72.73 \%)$ of participants with CKD were treated with $\mathrm{TDF}+3 \mathrm{TC}+\mathrm{EFV}$.

\section{Factors Associated with Chronic Kidney Disease}

In the bivariate logistic regression analysis, age, baseline WHO stage, BMI, having cancer, and isoniazid preventive therapy, were significantly associated with $\mathrm{CKD}(\mathrm{P}<0.25)$. When these variables were entered and analyzed in a multivariate logistic regression, only age greater than 50 years, and having cancer were significantly associated with CKD (AOR: $0.22,95 \% \mathrm{CI}=0.06-0.89, \mathrm{P}=0.033$, and AOR: 18.2, 95\% $\mathrm{CI}=1.22-271.77, \mathrm{P}=0.035$, respectively) (Table 3 ).

\section{Discussion}

The present study assessed prevalence of CKD and its associated factors in HIV-infected patients treated with a TDF-based regimen by using the CKD-EPI equation which is the recommended estimator of kidney function. In this study, $11(4.53 \%$ with $95 \% \mathrm{CI}=2.3-8 \%)$ participants had CKD, age $>50$ years and having cancer as comorbidity were found to be associated with CKD. The CKD prevalence $(4.53 \%)$ of the current study is in line 
Table I Socio-Demographic and Clinical Characteristics of Study Participants

\begin{tabular}{|c|c|c|c|}
\hline Variables & Category & Frequency & Percentage \\
\hline Sex & Female & 149 & 61.3 \\
\hline Education & $\begin{array}{l}\text { Do not read } \\
\text { and write } \\
\text { Only read } \\
\text { and write } \\
\text { Primary } \\
\text { Secondary } \\
\text { Tertiary }\end{array}$ & $\begin{array}{l}7 \\
3 \\
55 \\
116 \\
62\end{array}$ & $\begin{array}{l}2.9 \\
1.2 \\
22.6 \\
47.7 \\
25.5\end{array}$ \\
\hline Work & $\begin{array}{l}\text { Government } \\
\text { Private } \\
\text { Unemployed }\end{array}$ & $\begin{array}{l}62 \\
125 \\
56\end{array}$ & $\begin{array}{l}25.5 \\
51.4 \\
23\end{array}$ \\
\hline Marital status & $\begin{array}{l}\text { Single } \\
\text { Married } \\
\text { Divorced } \\
\text { Widowed }\end{array}$ & $\begin{array}{l}83 \\
101 \\
22 \\
37\end{array}$ & $\begin{array}{l}34.2 \\
41.6 \\
9.1 \\
15.2\end{array}$ \\
\hline WHO stage & $\begin{array}{l}\text { I } \\
\text { II } \\
\text { III } \\
\text { IV }\end{array}$ & $\begin{array}{l}54 \\
51 \\
89 \\
49\end{array}$ & $\begin{array}{l}22.2 \\
21 \\
36.6 \\
20.2\end{array}$ \\
\hline $\begin{array}{l}\text { Type of TDF-based } \\
\text { regimen }\end{array}$ & $\begin{array}{l}\text { TDF+3TC } \\
+\mathrm{EFV} \\
\text { TDF+3TC } \\
+\mathrm{ATV} / \mathrm{r}\end{array}$ & $\begin{array}{l}146 \\
97\end{array}$ & $\begin{array}{l}60.1 \\
39.9\end{array}$ \\
\hline $\begin{array}{l}\text { Cotrimoxazole } \\
\text { preventive therapy }\end{array}$ & Yes & 66 & 27.2 \\
\hline $\begin{array}{l}\text { Isoniazid preventive } \\
\text { therapy }\end{array}$ & Yes & 32 & 13.2 \\
\hline Tuberculosis & Yes & 4 & 1.6 \\
\hline Cancer & Yes & 8 & 3.3 \\
\hline Dyslipidemia & Yes & 44 & 18.1 \\
\hline $\begin{array}{l}\text { BMI }\left(\mathrm{kg} / \mathrm{m}^{2}\right), \text { median } \\
(\mathrm{IQR})\end{array}$ & \multicolumn{2}{|l|}{$24.2(5.8)$} & $\begin{array}{l}\operatorname{Min}=15.2 ; \\
\operatorname{Max}=39.8\end{array}$ \\
\hline $\begin{array}{l}\left.\text { CD4 (cells } / \mathrm{mm}^{3}\right) \text {, } \\
\text { median (IQR) }\end{array}$ & \multicolumn{2}{|l|}{$142(176)$} & $\begin{array}{l}\operatorname{Min}=7 \\
\operatorname{Max}=|4| 5\end{array}$ \\
\hline $\begin{array}{l}\text { SCR }(m g / d l), \text { median } \\
(I Q R)\end{array}$ & \multicolumn{2}{|l|}{$\mathrm{I}(0.3)$} & $\begin{array}{l}\operatorname{Min}=0.3 ; \\
\operatorname{Max}=2.9\end{array}$ \\
\hline
\end{tabular}

Abbreviations: BMI, body mass index; Max, maximum; Min, minimum; SCR, serum creatinine; WHO, World Health Organization.

with the findings of a study in Tikur Anbessa Specialized Hospital (TASH), 4.8\%. ${ }^{10}$ However, the finding was lower than the results of studies done in Asia, 9.86\%, ${ }^{8}$ Vietnam, $8.5 \%,{ }^{12}$ US Veterans, $14.3 \%,{ }^{11}$ and University of Gondar
Table 2 Stages of Kidney Functions Using the CKD-EPI Estimator in HIVIAIDS Patients Treated with TDF-based Regimen

\begin{tabular}{|l|l|l|l|}
\hline $\begin{array}{l}\text { Stage of } \\
\text { Kidney } \\
\text { Function }\end{array}$ & $\begin{array}{l}\text { GFR Estimation } \\
\text { (in ml/min) }\end{array}$ & Frequency & Percentage \\
\hline I & $\geq 90$ & 139 & 57.2 \\
\hline 2 & $60-89.9$ & 93 & 38.3 \\
\hline $3 a$ & $45-59.9$ & 7 & 2.9 \\
\hline $3 b$ & $30-44.9$ & 3 & 1.2 \\
\hline 4 & $15-29.9$ & 1 & 0.4 \\
\hline 5 & $<15$ & 0 & 0 \\
\hline CKD $\left(\right.$ GFR $\left.<60 \mathrm{ml} / \mathrm{min} / \mathrm{m}^{2}\right)$ & 11 & 4.5 \\
\hline
\end{tabular}

Abbreviations: CKD-EPI, chronic kidney disease epidemiology; GFR, glomerular filtration rate; CKD, chronic kidney disease.

Teaching Hospital. ${ }^{13}$ On the other hand, the result of the current study was higher than the finding of a study in Cape Town, South Africa, 2\%. ${ }^{7}$ The difference observed here might be because of variation in study design, lifestyle of participants, definition of CKD, baseline GFR, or methods used to estimate GFR.

Literatures revealed that older age, ${ }^{7,8,12,13}$ female sex, ${ }^{7}$ low BMI, ${ }^{12,13}$ and low CD4 count ${ }^{13}$ were significantly associated with CKD. In contrast, the present study showed no significant association of female sex, low BMI, and low CD4 count with CKD. Contrary to the previous studies, participants with older age ( $>50$ years old) was less likely to develop CKD in the present study (AOR: 0.22, 95\% $\mathrm{CI}=0.05-0.88, \mathrm{P}=0.033){ }^{7,8,12,13}$ The reason for this discrepancy might be the inclusion of more participants with age of less than or equal to 50 years old in the study.

Participants with cancer as comorbidity were 18 times more likely to develop CKD in the current study. This finding is supported by literatures that revealed higher staging and histology grades of endometrial cancers were associated with reduced GFR, ${ }^{20}$ and CKD was usually diagnosed in patients with cancer. Cancer treatment contributes to the development of $\mathrm{CKD}$ and its progression. ${ }^{21}$

The present study has the strength of being the first study to assess CKD in TDF-based regimens among HIV-infected patients in the study area. On the other hand, it has limitations of being cross-sectional, and a onetime determination of GFR which might not 
Table 3 Bivariate and Multivariate Analysis of Factors Associated with Chronic Kidney Disease in HIV/AIDS Patients Treated with TDF-Based Regimen

\begin{tabular}{|c|c|c|c|c|c|c|c|}
\hline \multirow[t]{2}{*}{ Variables } & \multirow[t]{2}{*}{ Category } & \multicolumn{2}{|c|}{ CKD } & \multirow[t]{2}{*}{ COR(95\% Cl) } & \multirow[t]{2}{*}{ P-value } & \multirow[t]{2}{*}{ AOR(95\% CI) } & \multirow[t]{2}{*}{ P-value } \\
\hline & & Yes & No & & & & \\
\hline Age (years) & $\begin{array}{l}\leq 50 \\
>50\end{array}$ & $\begin{array}{l}7 \\
4\end{array}$ & $\begin{array}{l}203 \\
29\end{array}$ & $\begin{array}{l}1.00 \\
0.25(0.07-0.91)\end{array}$ & 0.035 & $\begin{array}{l}1.00 \\
0.22(0.05-0.88)\end{array}$ & 0.033 \\
\hline BMI $\left(\mathrm{kg} / \mathrm{m}^{2}\right)$ & $\begin{array}{l}<18.5 \\
18.5-25 \\
>25\end{array}$ & $\begin{array}{l}2 \\
6 \\
3\end{array}$ & $\begin{array}{l}19 \\
110 \\
103\end{array}$ & $\begin{array}{l}1.93(0.36-10.28) \\
3.61(0.57-23.1) \\
1.00\end{array}$ & $\begin{array}{l}0.441 \\
0.175\end{array}$ & $\begin{array}{l}0.63(0.07-5.64) \\
0.6 \mathrm{I}(0.14-2.74) \\
1.00\end{array}$ & $\begin{array}{l}0.682 \\
0.522\end{array}$ \\
\hline WHO stage & $\begin{array}{l}\text { I } \\
\text { II } \\
\text { III } \\
\text { IV }\end{array}$ & $\begin{array}{l}1 \\
2 \\
6 \\
2\end{array}$ & $\begin{array}{l}53 \\
49 \\
83 \\
47\end{array}$ & $\begin{array}{l}1.00 \\
0.46(0.04-5.62) \\
0.26(0.03-2.23) \\
0.44(0.04-5.05)\end{array}$ & $\begin{array}{l}0.534 \\
0.220 \\
0.512\end{array}$ & $\begin{array}{l}1.00 \\
0.6 \mathrm{I}(0.05-7.40) \\
0.24(0.03-2.15) \\
1.23(0.05-29.12)\end{array}$ & $\begin{array}{l}0.694 \\
0.203 \\
0.897\end{array}$ \\
\hline Isoniazid & $\begin{array}{l}\text { Yes } \\
\text { No }\end{array}$ & $\begin{array}{l}3 \\
8\end{array}$ & $\begin{array}{l}29 \\
203\end{array}$ & $\begin{array}{l}2.63(0.66-10.46) \\
1.00\end{array}$ & 0.171 & $\begin{array}{l}3.24(0.7|-| 4.80) \\
1.00\end{array}$ & 0.130 \\
\hline Cancer diagnosis & $\begin{array}{l}\text { Yes } \\
\text { No }\end{array}$ & $\begin{array}{l}2 \\
9\end{array}$ & $\begin{array}{l}6 \\
226\end{array}$ & $\begin{array}{l}8.37(1.48-47.38) \\
1.00\end{array}$ & 0.016 & $\begin{array}{l}18.20(1.22-271.77) \\
1.00\end{array}$ & 0.035 \\
\hline
\end{tabular}

Note: $P<0.05$ set as statistically significant.

Abbreviations: BMI, body mass index; WHO, World Health Organization; COR, crude odds ratio; AOR, adjusted odds ratio; CKD, chronic kidney disease.

show the actual prevalence of CKD, and a relatively small sample size.

\section{Conclusion}

In the current study, the prevalence of CKD according to the glomerular filtration rate estimated by CKD-EPI equation was $4.53 \%(95 \% \mathrm{CI}=2.3-8 \%)$ which needs attention regarding TDF use. Age $>50$ years old, and having cancer as comorbidity were significantly associated with CKD. A prospective cohort study with long follow-up and large sample size is recommended to pinpoint the prevalence of $\mathrm{CKD}$ and its associated factors.

\section{Abbreviations}

AIDS, acquired immunodeficiency syndrome; ART, antiretroviral therapy; $\mathrm{CKD}$, chronic kidney disease; CKD-EPI, chronic kidney disease epidemiology; GFR, glomerular filtration rate; HIV, human immunodeficiency virus; SPSS, Statistical Package for Social Sciences; TDF, tenofovir disoproxil fumarate; TASH, Tikur Anbessa Specialized Hospital; WHO, World Health Organization; ZMH, Zewuditu Memorial Hospital.

\section{Data Sharing Statement}

Concerning the availability of data, it is permitted to get the data from the corresponding author upon rational request.

\section{Ethical Approval and Consent to Participate}

Before the start of the study, ethical approval was obtained from Institutional Ethical Review Board of College of Medicine and Health Sciences, Debre Berhan University. Subsequently, a permission letter was obtained from medical director of each hospital. The confidentiality of the participants was kept in such a way that patient identifiers were anonymized and the data in the software were protected with a password. The participants gave verbal informed consent after they were told about the purpose, method, and the ethical concern of the study. The participants' information was used only for the study purpose, and the study was performed based on the principles of the Declaration of Helsinki.

\section{Acknowledgment}

The authors would like to thank Debre Berhan University for financial support. Our thanks also shall go to medical director of TASH, and $\mathrm{ZMH}$, data collectors for their contribution to the completion of this study.

\section{Author Contributions}

All authors did significant contributions to conception and design of the study, acquisition of data, analysis and interpretation of data. In addition, all authors participated in drafting and revising the manuscript; agreed on the journal to which the manuscript is submitted; gave approval of the final version of 
the manuscript to be published and agreed to be accountable for all aspects of the work.

\section{Funding}

Debre Berhan University gave the financial support. The funding institution is not involved in any activities to prepare the manuscript and to approve the final manuscript for publication.

\section{Disclosure}

The authors declared that there is no conflicts of interest in this work.

\section{References}

1. USAIDS. Fact sheet-latest statistics on the status of the AIDS epidemic. 2020.

2. Kibret GD, Ferede A, Leshargie CT, Wagnew F, Ketema DB, Alebel A. Trends and spatial distributions of HIV prevalence in Ethiopia. Infect Dis Poverty. 2019;8(1):90. doi:10.1186/s40249-019-0594-9

3. Ekrikpo UE, Kengne AP, Bello AK, et al. Chronic kidney disease in the global adult HIV-infected population: a systematic review and meta-analysis. PLoS One. 2018;13(4):e0195443. doi:10.1371/journal. pone. 0195443

4. World Health Organization. Policy brief: update of recommendations on first-and second-line antiretroviral regimens. World Health Organization; 2019.

5. Mocroft A, Lundgren JD, Ross $\mathrm{M}$, et al. Cumulative and current exposure to potentially nephrotoxic antiretrovirals and development of chronic kidney disease in HIV-positive individuals with a normal baseline estimated glomerular filtration rate: a prospective international cohort study. Lancet HIV. 2016;3(1):e23-32. doi:10.1016/ S2352-3018(15)00211-8

6. Cuzin L, Pugliese P, Allavena C, et al. Antiretroviral therapy as a risk factor for chronic kidney disease: results from traditional regression modeling and causal approach in a large observational study. PLoS One. 2017;12(12):e0187517. doi:10.1371/journal.pone.0187517

7. Zachor H, Machekano R, Estrella MM, et al. Incidence of stage 3 chronic kidney disease and progression on tenofovir-based antiretroviral therapy regimens: a cohort study in HIV-infected adults in Cape Town, South Africa. AIDS. 2016;30(8):1221. doi:10.1097/QAD.000 0000000001041

8. Suzuki S, Nishijima T, Kawasaki Y, et al. Effect of tenofovir disoproxil fumarate on incidence of chronic kidney disease and rate of estimated glomerular filtration rate decrement in HIV-1-infected treatment-naïve Asian patients: results from 12-year observational cohort. AIDS Patient Care STDS. 2017;31(3):105-112. doi:10.1089/apc.20 16.0286
9. Nishijima T, Kawasaki Y, Mutoh Y, et al. Prevalence and factors associated with chronic kidney disease and end-stage renal disease in HIV-1-infected Asian patients in Tokyo. Sci Rep. 2017;7(1):1-8. doi:10.1038/s41598-017-15214-x

10. Yazie TS, Orjino TA, Degu WA. Reduced kidney function in tenofovir disoproxil fumarate based regimen and associated factors: a hospital based prospective observational study in Ethiopian patients. Int J Nephrol. 2019;2019:1-9. doi:10.1155/2019/9172607

11. Sutton SS, Magagnoli J, Hardin JW, et al. Association of tenofovir disoproxil fumarate exposure with chronic kidney disease and osteoporotic fracture in US veterans with HIV. Curr Med Res Opin. 2020;36(10):1635-1642. doi:10.1080/03007995.2020.1816538

12. Hoang CQ, Nguyen HD, Vu HQ, et al. Determinants of risk factors for renal impairment among HIV-infected patients treated with tenofovir disoproxil fumarate-based antiretroviral regimen in Southern Vietnam. Biomed Res Int. 2020;2020.

13. Ahmed E, Diro E, Hailu W, Muhie OA. Assessment of renal dysfunction and associated factors among patients on tenofovir based antiretroviral treatment at Gondar University Hospital, North West Ethiopia: retrospective institution based cross sectional study. J AIDS HIV Res. 2020;12(2):34-44. doi:10.5897/JAHR2019.0498

14. Alfano G, Guaraldi G, Fontana F, Bellasi A, Cappelli G. Therapeutic management of HIV-infected patients with chronic kidney disease. J Nephrol. 2020;4:1-5.

15. Giordano TP, Guzman D, Clark R, Charlebois ED, Bangsberg DR. Measuring adherence to antiretroviral therapy in a diverse population using a visual analogue scale. HIV Clin Trials. 2004;5(2):74-79. doi:10.1310/JFXH-G3X2-EYM6-D6UG

16. Kobin AB, Sheth NU. Levels of adherence required for virologic suppression among newer antiretroviral medications. Ann Pharmacother. 2011;45(3):372-379. doi:10.1345/aph.1P587

17. Levey AS, Eckardt KU, Tsukamoto Y, et al. Definition and classification of chronic kidney disease: a position statement from kidney disease: improving global outcomes (KDIGO). Kidney Int. 2005;67 (6):2089-2100. doi:10.1111/j.1523-1755.2005.00365.x

18. Ibrahim F, Hamzah L, Jones R, Nitsch D, Sabin C, Post FA. Comparison of CKD-EPI and MDRD to estimate baseline renal function in HIV-positive patients. Nephrol Dial Transplant. 2012;27 (6):2291-2297. doi:10.1093/ndt/gfr657

19. Levey AS, Stevens LA, Schmid CH, et al. A new equation to estimate glomerular filtration rate. Ann Intern Med. 2009;150 (9):604-612. doi:10.7326/0003-4819-150-9-200905050-00006

20. Premuzic V, Kruezi E, Berovic M, et al. The association of the decline in glomerular filtration rate with aggressive endometrial cancers. Int Urol Nephrol. 2020;52(1):161-168. doi:10.1007/s112 55-019-02324-w

21. e Silva V, Costalonga EC, Coelho FO, Caires RA, Burdmann EA. Assessment of kidney function in patients with cancer. Adv Chronic Kidney Dis. 2018;25(1):49-56. doi:10.1053/j.ackd.2017.10.010
HIV/AIDS - Research and Palliative Care is an international, peerreviewed open-access journal focusing on advances in research in HIV, its clinical progression and management options including antiviral treatment, palliative care and public healthcare policies to control viral spread. The manuscript management system is completely online and includes a very quick and fair peer-review system, which is all easy to use. Visit http://www.dovepress.com/testimonials.php to read real quotes from published authors. 